\title{
Recommended Phyto-Ameliorative Restoration of Vegetation in Ganja Surroundings Rivers
}

\author{
*Natiga Ismayilzade, **Abbas Ismailov, ** Narmin Sadigova, ***Sayyara Ibadullayeva \\ *Ganja State University, \\ **Azerbaijan State Agrarian University, \\ ***Botany Institute of the Azerbaijan National Academy of Sciences
}

\begin{abstract}
In this article, there is information about implementation of fito-ameliorative measures in Ganja surroundings rivers area exposed to erosion. Selection of plant species in accordance with existing environmental conditions, possessing a strong root system and drought-resisting of selected plants is a very important issue in order to solve these problems. On the other hand, preventing trees and shrubs cutting in meadow and forest groups, preventing pasturing in areas are shown as the main issues in order to prevent these processes. Considering all of these it is advisable to implement the following measures in the territory: conducting monitoring and inventoring lands in order to keep natural potential of vegetation; implementation of complex measures in order to prevent degradation of pland and land cover and erosion of mountain lands; planting trees and protective forest lines for relatively strong mountain slopes, implementation of fito-ameliorative measures in expanded fields of rivers and streams, areas prone to landslides; strict observance of the reserve regime.
\end{abstract}

Keywords: Ganja surroundings rivers, fito-ameliorative measure, trees and shrubs

\section{INTRODUCTION}

Negative factors caused to erosion and other natural and anthropogenic factors in the vegetation in the territory of Ganja river basins have been mentioned and phyto-ameliorative measures have been advised for restoration of the vegetation in the article. It has been considered restoration of basically taproot system of trees, shrubs and herbaceous plants in degraded areas through reintroduction. For that, up to 60 plant seeds have been sown in 18 polluted and degraded area.

Unequal distribution of rainfall according to seasons, dry summer, harsh winter, continental climate influences on formation of land and vegetation of the area. Arid climate in Ganja forms soils with simple structure that are result of physical and mechanical weathering of mountain rocks, and vegetation. In accordance with primarity of land and rocks, rough relief, weak constipation of plants, urbanization, rainfall, snow melting streams causes to erosion and flood. Subsequently soil formation process weakens and prevents development of plants and decreases productivity of soil. Moreover, deterioration of the river regime in the area and their tributaries damages agriculture and roads, buildings in residential areas. All of these restrict potential land use, vegetation period longers up to 8 months, increases sun radiation and it is required implementation of protective measures for prevention of erosion made by metal mine.

Thus, problems of prevention erosion and flood consist of complex measures. They are included forestation of mountain slopes. A number of investigations are carried out against erosion processes [Alakbarov, 1967; Novruzov et al., 1998]

Erosion processes, flood result with losing nutrients from soil and demolishing soil. These factors destroy productive condition where forest formations develop and make it difficult restoration of vegetation and cultivation of with supplementary and hydro technical mechanisms. So, restoration of vegetation that is always exposed to floods and phyto-ameliorative measures to develop them are important. Moreover, 
preventing of overloading of fodder areas near river basins, forestation of slopes are one of the main scientific-practical problems.

\section{MAterials AND Method}

The research was carried out in 2009-2015 near Ganja. The aim consists of the studing the phytoameliorative importance of river basins (Ganjachay, Turyanchay, Kurekchay and Aghsuchay, Shamkir Water reservoir).

Geobotanical notes were carried out in areas in size of 10x10 m. Sample areas are chosen from every vegetation types being $1 \mathrm{~m}^{2}$, then $5 \mathrm{~m}^{2}$ and $10 \mathrm{~m}^{2}$ in order to study plant resource and thickness [Flint et all., 2002]. Structure, composition, the number of species, and dominants and edificators, in one word, floristic-geobotanical indicators were studied [Yareshenko, 1953,1967] and the richness of flora mentioned in Drude 5 graded measure [Drude, 1887].

Classical and modern botanical-floristical, systematic, environmental, aerological and statistical methods were used in the development of the herbarium materials from the basin [Asgerov, 2005-2008; Ismailov, 2009; Алексеев et all, 1989; Federchuk, 1979; Flora Azerbai..., 1950-1961].

\section{EXPERIMENTAL SECTION}

Before solving these problems it is necessary to take into account that formation of mesophyl forests in areas where xerophyte forests form is only possible in case of anthropogenic factors. The main factors are developing soil rocks and water regime. Instruction of hydrotechnical system in form of terrace will be able to solve the problem. Terraces cause to accumulating additional moisture as well as prevent soil washing. In most cases, it is possible to water phyto-ameliorants planted in strong inclinated slopes. It must be constructed stone walls, protection bans that keep water and canals in the process.

Construction of water sources in banks of Ganjachay, Aghsuchay, Turyanchay, Kurekchay rivers \& Shamkir Water reservoir has great importance. Considering the prospectively of agriculture and economics, overloading the river basins requires the installation of an artificial river water sources. As a result, the threat of flood decreases, irrigation of phyto-ameliorations and reusage of agriculture lands were carried out.

Formation of terraces and forests in basin slopes should be organized according to lowland and highland mountainous parts which have suitable condition for trees and brushes. Measures that carried out in fodder areas should focused on their developing. It is recommended to select plants in order to develop the slopes in highland areas. Strong root system plants improve the top layer of the soil and prevent water wash and erosion. These types of grass are eaten by livestock. Therefore, their usage in agriculture is perspective. Accordingly against erosion of slopes, sowing of sod-forming grass seeds, carrying out engineering and technical and agro technical work, construction of hydro technical facilities, and so on, are very necessary measures.

One of the important issues is to improve river bank soils and restore soil that exposed to erosion. Mines, stone-sand quarries, and so on are situated in Ganja and near regions, so it is common to see pollution more than 2 times. So, research that is conducted by us focused on vertical variation of the trees, bush, semi bush, perennial grasses. In addition, the root system of plants and growing properties within every zone were studied. Necessary to note that plants that form top layers are scattered and they are not common for all latitude zones. Only perennial grain crop Festuca sclerophylla and Poa bulbosa grow mountain foot areas. $70-80 \mathrm{~cm}$ height and $15-20 \mathrm{~cm}$ root of these plants protect sharp slopes from washing. Thus, their roots that go through $30-40 \mathrm{~cm}$ depth penetrate rocks and form root system. These kinds grain crop protect slopes from washing.

Mountain-xerophyte Thymus species are plants with short bushes that laid on the ground. Mature plants cover 20-30 cm square, depth of roots are 1.5-2 $\mathrm{m}$ and protect slope. 
Scorzenera species that is spread in Middle mountain zone of river basins have thick root that goes through soil up to $30-50 \mathrm{~cm}$. systematically and morphologically these species are different, however, root systems are similar and it is also good for protecting from erosion.

Achillea species give 2500 seeds and can grow by the vegetative way and form a lot of branches. They can develop well in less fertile soils and are tolerant for intensive grazing and are planted in areas where exposed to erosion.

Artemisia types are common in territory. They are generally found in lowland zones and plains. Wormwood almost reproduces by the vegetative ways. They are used in restoration of eroded areas.

Jurinea types reproduce by vegetative way through the roots of the plants. J.spectabilis are found in rocks of Alp zones while others are found in lower and secondary mountainous zones. All of them are in height of 20-60 (70) $\mathrm{cm}$ that are perennial plants. The roots of these species can penetrate to a depth of $40-50 \mathrm{~cm}$. Jurinella subacaulisis a plant that has no stems.

Above mentioned plants reproduce by root so it is used against erosion.

Plants that are deprived of such features can also live. The roots of plants are taproot, but adapted to moving substrata. Development of extensive root system is characteristic for them. Height of young Eryngium species belonging to the genus of the family Apiaceae is $2-5 \mathrm{~cm}$, while their main root goes to depth of $20-25 \mathrm{~cm}$. The main stem of the root reaches to a depth of 50-60 cm in mature plants, in $15-20$ $\mathrm{cm}$ forms many lateral roots. They are considered the best fixation of soils. Prangos ferulacea and other types of family Prangos acaulis, P.uloptera, P.lophoptera are phytomeliorants that have a strong taproot system.

Upper part of young Oxytropis is 3-5 cm and underground part is $10-15 \mathrm{~cm}$. Strong developed roots of mature ones are covered with small roots going to 15-20 $\mathrm{cm}$ depth. Upper part of young Hedysarum formosum is $3-5 \mathrm{~cm}$ while underground part is not less than $10-15 \mathrm{~cm}$. It can be used in actions against slope erosion as phyto-ameliorative.

All types of species of Onobrychis have a strong taproot system. O.transcaucasica has thick main root and goes to $10 \mathrm{~cm}$ of depth, $5-7 \mathrm{~cm}$ from the main root starts lateral roots in length of $20-25 \mathrm{~cm}$. The main root of O. hajastana can reach to the deepest layers of soil and take up water, are tolerant for drought. All of these are the best fixation of weathered slopes.

Medicago species are perennial plants that spread in lower, middle, and high zones, have well developed taproot with many lateral roots. Roots of M.caucasica in the first year of vegetation can reach up to 60-80 $\mathrm{cm}$ and mature species can reach to depth of $10 \mathrm{~m}$. Medicago species spread on the ground and fix substrate and preserve the soil disintegration to fine parts.

In the high mountainous zone Medicago is replaced with Trifolium and Amoria. All species of Trifolium and Amoria have role in fixing the soil. Trifolium and Amoria may reproduct by seeds as well as vegetative ways and perennial plants.

Annual, perennial, and tragacant forms of Astragal species are common in the area. Root of annual Astragal is weak while roots of perennial plants go to deep layers. Roots of tragacant forms can reach 2-3 $\mathrm{m}$ depth, 3-4 m width. For this reason, they are endurable to drought. Lateral roots developed well so, the plant is renewed by them. They can grow in all type of soil. They reproduce by seed, however, they grow weakly, so it needs to be sown in autumn.

Apart from above mentioned plants Ononis, Lathyrus, Glycyrrhiza and so on,also have these properties. It must be used grain crop such as Elitrigia, Agrostis, Cynodon, Koeleria, Stipa and others for phytoamelioration.

There are 3 forms of the root system of Salsola nodulosa: 1 . Spread on land surface; 2. highly developed taproot; 3. Poor developed taproot. The main root of Salsola nodulosa is $2.2 \mathrm{~cm}$ length, goes to $6-25 \mathrm{~cm}$ depth. They form a number of first degree roots that grow horizontally. These side roots form second 
degree roots and width of the main root becomes $1-2 \mathrm{~cm}$ going to the depth of $3 \mathrm{~cm}$ is divided into 2 part. One of them grows vertically, another grows horizontally. Thus, Salsola nodulosa is used for preventing of soil erosion in lower mountainous zones.

Mespilus germanica is a plant in height of 3-4 (5) $\mathrm{m}$ that have strong developed root system that grows in slopes of bright colored forests. Its root system covers $15 \mathrm{~m}^{3}$ of land. They have taproot as well as lateral roots. Mespilus germanica is common in Tugay forests. Around Turyanchay is surrounded such forests.

Height of brushes of different individuals of Rosa species is 2-3 (4) $\mathrm{m}$. They have slow growing root system. Rosa species reproduce by root and covers all zones of the basin.

As phyto-ameliorant Paliurus spina-christi grow on the south slopes and stony areas. Its height is 2-3 (5) $\mathrm{m}$, has the strong root system.

Quercus macranthera forms weakly developed root system during first four years. Mature individuals develop strong root system. Fraxinus excelsior also has surface type of root system. It grows in high mountainous zones of the basin.

Atraphaxis reproduces both vegetative ways and by seeds such as Atraphaxis spinosa, A. angustifolia and they are initial fixation of slopes that are exposed to erosion.

Campanula, Dianthus, Nepeta, Teucrium, Scutellaria, Dracocephalum, Stachys, Salvia, and Poa species have properties to adopt and live on substrates that exposed to erosion.

Perennial Heracleum species that form endurable biomass in summer and perish in winter in middle and highland areas are tha main components of proluvial - gravel sediments. Thus, their large leaves cover the land and prevent it of drying and create condition for other plants. Heracleum both in proluvial and sediments reproduce by root, however, wild individuals are rather short. It is given areas within height zones that differ from each other according to physical - geographical conditions. and is given meliorative measures scheme that is considered to carry out (scheme 1.)

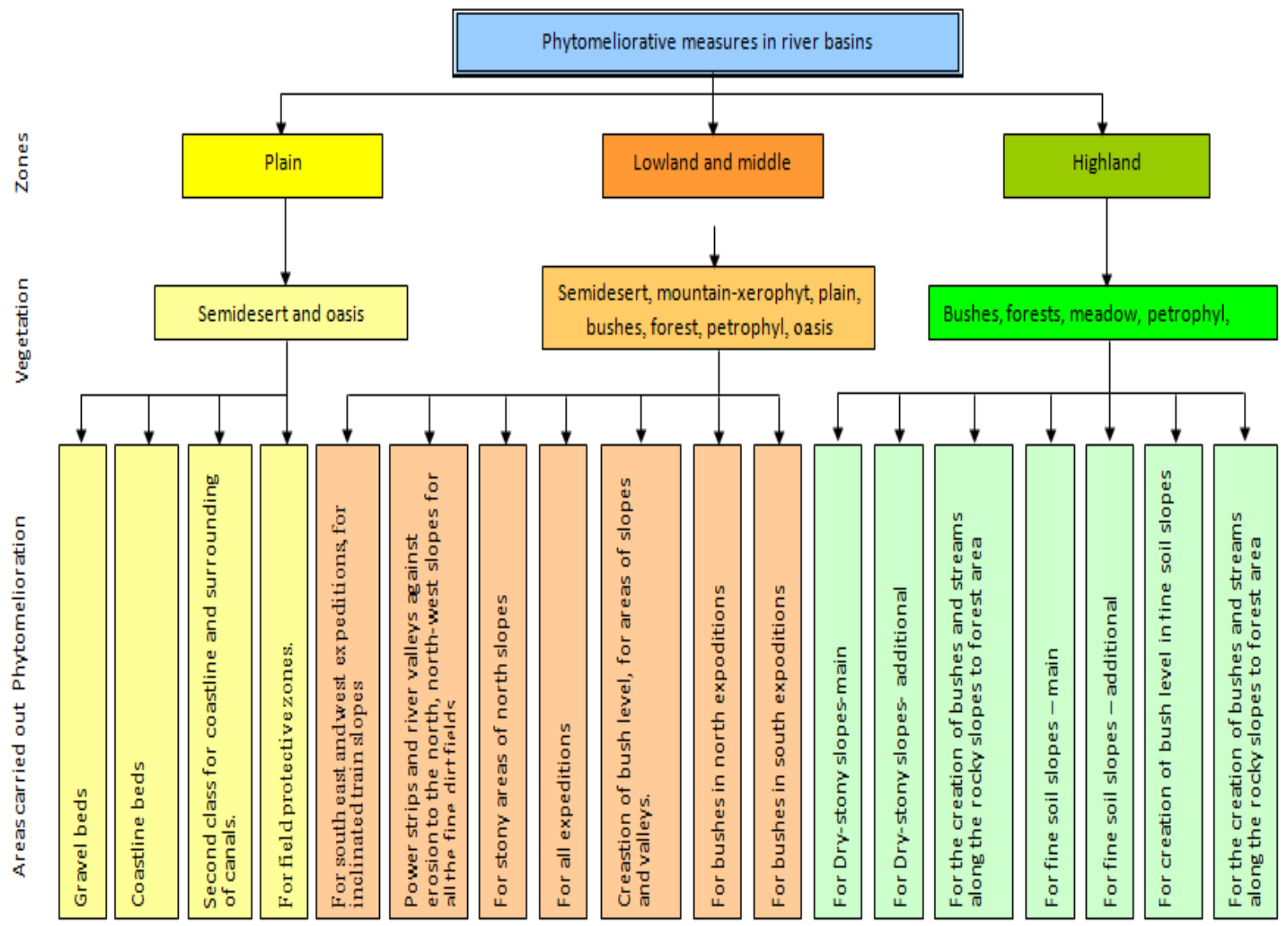




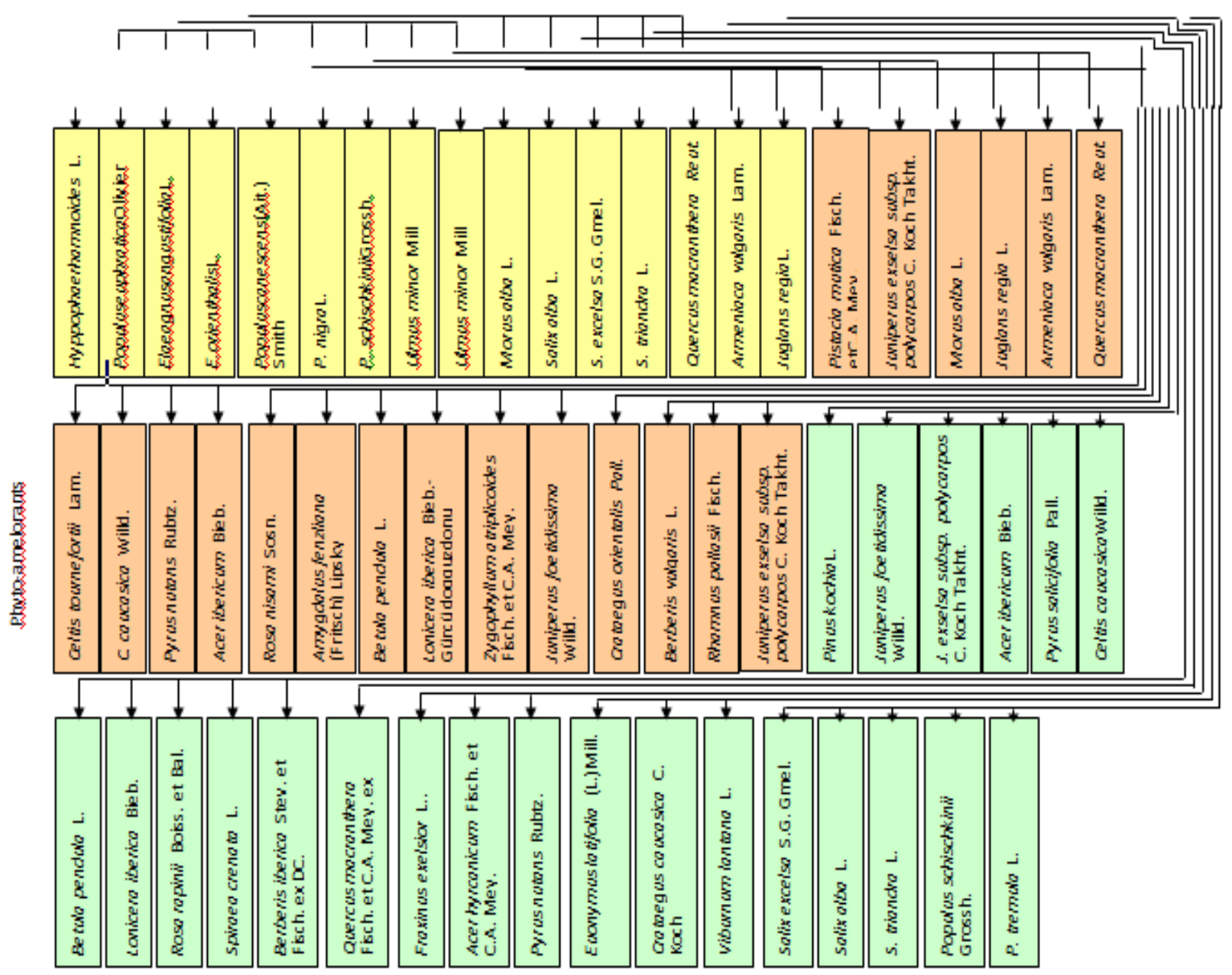

Scheme1. Phyto-Melorants Elected for Waist-Bands

Considering all of these it is advisable to implement the following measures in the territory:

- conducting monitoring and inventorying lands in order to keep natural potential of vegetation;

- implementation of complex measures in order to prevent degradation of plant and land cover and erosion of mountain lands;

- planting trees and protective forest lines for relatively strong mountain slopes, implementation of phyto-ameliorative measures in expanded fields of rivers and streams, areas prone to landslides;

- strict observance of the reserve regime.

\section{REFERENCES}

Alakbarov K.A. 1967. Land protection of erosion. Baku, Azarnesr, 221p.

Asgerov A.M. 2005, 2008. The higher plants of Azerbaijan (the review of Azerbaijan flora): 3 volumes, I - III v., Baku, Elm,

Alekseev Y.B., Gubanov I.A., Tichamirov V.N. 1989. Botanical nomenclatura. M .: MGU, 168 c.

Novruzov V.S., Gurbanov E.M., Z.M. Ismayılova 1998. Plant ecology (with geobotanical basis). Baku State University, $197 \mathrm{p}$.

Drude O. 1887. Atlas der Pflanzenver breitung (Berghaus physikalis cheratlas, abeitung). Gotha, p 6-52.

Ismailov A.H. 2009. Trees and bushes of Gilancay basin, their phyto-ameliorative importance //scientific works of Nakhchivan State University. Natural sciences and medical series, №1 (26), p. 51-57 


\section{Natiga Ismayilzade et al.}

Federchuk A.T. 1976. Botanical geography (field experience). Minsk: BGU, 223 p. Flint B.Y., Smirnova O.V. et all. 2002. Keeping and protecting of the biological variety M.: 289 p.

Flora Azerbaijan: 1950-1961 T. 1-8, Baku: SA-Azerbaijan,

Yaroshenko P.D.1953. Bases of learning of the plant cover. M ., 351 p.

Yaroshenko P.D..1967. Methods of learning of the plant stock // Bot. jour. №4, p. 27-31 